\title{
A New Antibacterial Dioxopiperazine Alkaloid Related to Gliotoxin from a Marine Isolate of the Fungus Pseudallescheria
}

\author{
Xifeng Li ${ }^{\dagger}$, Se-Kwon Kim, Ki Wan Nam, Jung Sook Kang, Hong Dae Choi, \\ Byeng Wha Son
}

Received: February 2, 2006 / Accepted: April 7, 2006

(C) Japan Antibiotics Research Association

\begin{abstract}
A new antibacterial dioxopiperazine, dehydroxybisdethiobis(methylthio)gliotoxin (1), and the previously described bisdethiobis(methylthio)gliotoxin (2) and gliotoxin (3), have been isolated from the broth of a marine-derived fungus of the genus Pseudallescheria. The structure and absolute stereochemistry of the new compound was assigned on the basis of NMR and CD experiments. Compounds $\mathbf{1} \sim \mathbf{3}$ exhibit potent antibacterial activity against the methicillin-resistant and multidrugresistant Staphylococcus aureus with MIC values of 31.2, 31.2, and $1.0 \mu \mathrm{g} / \mathrm{ml}$, respectively. Compound $\mathbf{3}$ also exhibited a significant radical scavenging activity against 1,1-diphenyl-2-picrylhydrazyl (DPPH) with $\mathrm{IC}_{50}$ value of $5.2 \mu \mathrm{M}$.
\end{abstract}

Keywords marine-derived fungus Pseudallescheria, dehydroxybisdethiobis(methylthio)gliotoxin, bisdethiobis(methylthio)gliotoxin, gliotoxin, antibacterial activity, radical scavenging activity

B. W. Son (Corresponding author), X. Li, S.-K. Kim: Department of Chemistry, Pukyong National University, Busan 608-737, Korea, E-mail: sonbw@pknu.ac.kr

K. W. Nam: Department of Marine Biology, Pukyong National University, Busan 608-737, Korea

J. S. Kang: College of Dentistry, Pusan National University, Busan 602-739, Korea

H. D. Choi: Department of Chemistry, Dongeui University, Busan 614-714, Korea

† Present address: Analysis Measurement Center, Yanbian University, Jilin 133002, P.R. China
Marine microorganisms such as bacteria and fungi inhabit virtually any environment in the sea, and they are the source of greatest diversity in the sea $[1,2]$. These microbes have been shown to produce novel substances with utilities as potential new drug leads [3].

In our screening aimed at identifying antimicrobial compounds of microbial origin [4], we investigated antibacterial activity against the methicillin-resistant and multidrug-resistant Staphylococcus aureus (MRSA and MDRSA) from the fungal extracts, and a significant activity was observed in the marine-derived algicolous fungus Pseudallescheria sp. (MFB165).

\section{Fungal Isolation and Culture}

The fungal strain, Pseudallescheria sp., was isolated from the surface of the marine brown alga Agarum cribrosum collected in the Uljin, Gyeongbuk Province, Korea in 2002 and identified based on the morphological evaluation and fatty acid methyl ester analysis (Korean Culture Center of Microorganism, Seoul, Korea, a similarity index of 0.65). A voucher specimen is deposited at Pukyong National University with the code MFB165.

The isolate was cultured in ten $\times$ one liter volumes using SWS medium consisting of soytone $0.1 \%$, soluble starch $1.0 \%$, and seawater $100 \%$ for 30 days (static) at $29^{\circ} \mathrm{C}$.

\section{Extraction and Isolation}

The mycelium and broth were separated by filtration, and the whole broth was extracted with EtOAc (10 liters) to afford crude extract of $0.8 \mathrm{~g}$. The broth extract showed strong antibacterial activity against MRSA and MDRSA, 


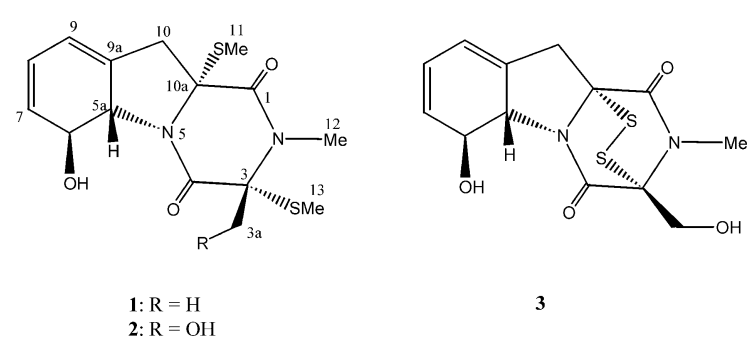

Fig. 1 Chemical structures of dehydroxybisdethiobis(methylthio)gliotoxin (1), bisdethiobis(methylthio)gliotoxin (2), and gliotoxin (3).

and the active components were purified by assay-guided isolation.

Broth extract $(0.8 \mathrm{~g})$ was subjected to silica gel flash chromatography and eluted with $n$-hexane/EtOAc $(1: 1), n$ hexane/EtOAc ( $1: 5), n$-hexane/EtOAc $(1: 10)$, and finally with EtOAc. Each collections $(30 \mathrm{ml}$ each) were combined on the basis of their TLC profiles to yield four major fractions. MPLC of antibacterial active fractions 2, 3, and 4 on ODS (YMC Gel, ODS-A, $12 \mathrm{~nm}, \mathrm{~S}-150 \mu \mathrm{m}$ ) by elution with $\mathrm{MeOH}$ afforded compounds $\mathbf{1} \sim \mathbf{3}$, respectively. The isolated compounds were further purified by HPLC (YMC ODS-A, $10 \times 250 \mathrm{~mm}, 1 \mathrm{ml} /$ minute) utilizing a 30 minutes gradient program of $50 \%$ to $100 \% \mathrm{MeOH}$ in $\mathrm{H}_{2} \mathrm{O}$ to furnish dehydroxybisdethiobis(methylthio)gliotoxin $(\mathbf{1}, 5.5 \mathrm{mg}$ ), bisdethiobis(methylthio)gliotoxin $(2,9.0 \mathrm{mg}$ ) and gliotoxin $(\mathbf{3}, 7.0 \mathrm{mg})$, respectively.

Dehydroxybisdethiobis(methylthio)gliotoxin (1): a colorless oil; $[\alpha]_{\mathrm{D}}^{20}=-48^{\circ}(c 0.3, \mathrm{MeOH}) ; \mathrm{CD}(\mathrm{MeOH}) \mathrm{nm}$ $(\Delta \varepsilon) 287(+2.8), 225(-7.5)$; UV $\lambda_{\max }^{\mathrm{MeOH}} \mathrm{nm}(\log \varepsilon) 271$ (4.25); IR (KBr) $v_{\max } 3360,1661,1641,1423,1383,1255$, $1189,1062,960 \mathrm{~cm}^{-1}$; LR-EI-MS m/z $340[\mathrm{M}]^{+}(0.3), 323$ (1), 309 (2), 293 (74), 265 (16), 246 (55), 245 (67), 218 (58), 56 (100). HR-FAB-MS $m / z 363.0816[\mathrm{M}+\mathrm{Na}]^{+}$ (calcd for $\mathrm{C}_{15} \mathrm{H}_{20} \mathrm{~N}_{2} \mathrm{O}_{3} \mathrm{~S}_{2} \mathrm{Na}, 363.0813$ ). See Table 1 for NMR spectral data.

Bisdethiobis(methylthio)gliotoxin (2), $[\alpha]_{\mathrm{D}}^{20}=-51^{\circ}(c$ $1.0, \mathrm{MeOH})$, and gliotoxin (3) were isolated as a colorless oil and white solid, respectively, and showed spectral data virtually identical to those reported in the literature [5 7].

\section{Structural Elucidation and Bioactivity}

Compounds $\mathbf{2}$ and $\mathbf{3}$ were identified as the known compounds, bisdethiobis(methylthio)gliotoxin and gliotoxin, respectively, by comparison of their spectroscopic data to the published data [5 7].

Dehydroxybisdethiobis(methylthio)gliotoxin (1), $[\alpha]_{\mathrm{D}}$ $-48^{\circ}$ ( c 0.3, MeOH), was isolated as a colorless oil which yielded a molecular formula of $\mathrm{C}_{15} \mathrm{H}_{20} \mathrm{~N}_{2} \mathrm{O}_{3} \mathrm{~S}_{2} \mathrm{Na}$ by HR-
Table 1 NMR spectral data for dehydroxybisdethiobis(methylthio)gliotoxin (1) ${ }^{\text {a }}$

\begin{tabular}{|c|c|c|c|}
\hline C no. & $\delta_{\mathrm{H}}$ (mult., J) & $\delta_{\mathrm{C}}(\mathrm{mult})$ & $\begin{array}{l}\mathrm{HMBC} \\
(\mathrm{H} \text { to } \mathrm{C})\end{array}$ \\
\hline 1 & & 164.3 (s) & \\
\hline 3 & & 67.3 (s) & \\
\hline $3 a$ & $1.81(\mathrm{~s})$ & 23.2 (q) & 3,4 \\
\hline 4 & & 167.4 (s) & \\
\hline $5 a$ & $4.79(d, 13.5)$ & 68.9 (d) & 6 \\
\hline 6 & $4.68(d, 13.5)$ & 73.6 (d) & $5 a$ \\
\hline $6-\mathrm{OH}$ & 5.46 (br.s) & & 6,7 \\
\hline 7 & $5.62(d, 9.7)$ & $130.4(d)$ & $5 a, 9$ \\
\hline 8 & $5.89(\mathrm{~m})$ & $123.4(d)$ & \\
\hline 9 & 5.96 (br.s) & 118.8 (d) & \\
\hline $9 a$ & & 133.5 (s) & \\
\hline 10 & $3.03(\mathrm{~s})$ & $37.9(\mathrm{t})$ & $9,9 a, 10 a$ \\
\hline $10 a$ & & 71.6 (s) & \\
\hline 11 & $2.16(\mathrm{~s})$ & 14.1 (q) & $10 a$ \\
\hline 12 & $2.98(\mathrm{~s})$ & 28.7 (q) & 1,3 \\
\hline 13 & $2.21(\mathrm{~s})$ & 14.5 (q) & 3 \\
\hline
\end{tabular}

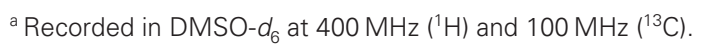

FAB-MS $\left[(\mathrm{M}+\mathrm{Na})^{+} \mathrm{m} / z 363.0813(\mathrm{dev}+0.3 \mathrm{ppm})\right]$ and ${ }^{13} \mathrm{C}$ NMR methods. The IR spectrum of 1 exhibited bands characteristic for hydroxyl $\left(3360 \mathrm{~cm}^{-1}\right)$ and amide $\left(1661 \mathrm{~cm}^{-1}\right)$ functionalities, while the UV spectrum revealed the presence of a dioxopiperazine $[271 \mathrm{~nm}(\log \varepsilon$ 4.25)] chromophore. The EI-MS spectrum of dioxopiperazine 1 showed two prominent fragment ions corresponding to the parent molecule with losses of one and two $\mathrm{CH}_{3} \mathrm{~S}$ groups $\left[m / z 293\left(\mathrm{M}^{+}-\mathrm{CH}_{3} \mathrm{~S}\right), 246\right.$ $\left.\left(\mathrm{M}^{+}-2 \mathrm{CH}_{3} \mathrm{~S}\right)\right]$, respectively.

The ${ }^{1} \mathrm{H}$ and ${ }^{13} \mathrm{C}$ NMR data for dioxopiperazine $\mathbf{1}$, including results from COSY, DEPT, HMQC and HMBC experiments, showed the presence of a $N, N$-disubstituted dioxopiperazine ring possessing one methyl and two thiomethyl groups, 2,3-disubstituted-3,5-cyclohexadien-1ol, and one methylene (Table 1). The connectivities and assignments of the carbon and proton resonances for $\mathbf{1}$, which led to the planar structure for this metabolite, were made by interpretation of HMBC NMR data and by the comparison of the NMR data with those of bisdethiobis(methylthio)gliotoxin (2). The general features of its UV, IR, CD and NMR spectra closely resembled those of compound 2, except that the NMR signals assigned to the hydroxymethyl $[\delta 3.73,4.05$ (each $1 \mathrm{H}$, dd, $\left.J=11.3,6.0,3 \mathrm{a}-\mathrm{H}_{2}\right), 5.50(1 \mathrm{H}, \mathrm{t}, J=6.0,3 \mathrm{a}-\mathrm{OH}), \delta_{\mathrm{C}} 63.0$ (t, C-3a)] for compound 2 were changed to the methyl group $\left[\delta 1.81\left(3 \mathrm{H}, \mathrm{s}, 3 \mathrm{a}-\mathrm{H}_{3}\right), \delta_{\mathrm{C}} 23.2(\mathrm{q}, \mathrm{C}-3 \mathrm{a})\right]$ for 
compound $\mathbf{1 .}$

The relative configurations at the stereocenters were deduced from NOE spectral data which showed correlations between 3-SCH 3 and $10 \mathrm{a}-\mathrm{SCH}_{3}$ and between $5 \mathrm{a}-\mathrm{H}$ and $6-\mathrm{OH}$ and $10-\mathrm{H}_{\mathrm{a}}$ indicative of their cis orientations, respectively.

The absolute stereochemistry of $\mathbf{1}$ was investigated using CD. The CD spectrum of $\mathbf{1}$ showed the following Cotton effects at $287 \mathrm{~nm}(\Delta \varepsilon,+2.8)$ and $225 \mathrm{~nm}(\Delta \varepsilon,-7.5)$, which were very similar to those of $2[278 \mathrm{~nm}(\Delta \varepsilon,+3.6)$ and $226 \mathrm{~nm}(\Delta \varepsilon,-7.5)]$. Thus, the absolute configuration of asymmetric centers for $\mathbf{1}$ was determined to be $3(R)$, $5 \mathrm{a}(S), 6(S)$, and $10 \mathrm{a}(R)$. This conclusion was further supported by the comparison of the optical rotation between compounds $\mathbf{1}$ and 2 . The value of specific rotation of $1\left([\alpha]_{\mathrm{D}}-48^{\circ}\right)$ was in negative, the same phase as that of $2\left([\alpha]_{\mathrm{D}}-51^{\circ}\right]$, implying that both compounds shared the same configuration.

Compounds $1 \sim 3$ were evaluated for antibacterial activity against MRSA and MDRSA [8], and they exhibited an antibacterial activity with MIC values of $31.2,31.2$, and $1.0 \mu \mathrm{g} / \mathrm{ml}$, respectively. Compounds $\mathbf{1} \sim \mathbf{3}$ were also screened for radical scavenging activity against DPPH [9]. Only 3 showed a significant radical scavenging activity with $\mathrm{IC}_{50}$ value of $5.2 \mu \mathrm{M}$, which is more potent than the positive control, ascorbic acid $\left(\mathrm{IC}_{50}, 20 \mu \mathrm{M}\right)$, and the $\mathbf{1}$ and 2 were virtually inactive.

Diketopiperazines are widespread microbial products commonly found in nutrient rich cultures of both terrestrial and marine fungi [10]. Diketopiperazines are of interest because of their activity in various pharmacological assay systems [6].

Acknowledgements X.L. acknowledges the support of the Brain Korea 21 (BK21) (F020). Mass and CD spectral data were kindly provided by the Korea Basic Science Institute. This work was supported by a grant from MarineBio21, Ministry of Maritime Affairs and Fisheries, Korea.

\section{References}

1. Blunt JW, Copp BR, Munro MHG, Northcote PT, Prinsep MR. Marine natural products. Nat Prod Rep 22: 15-61 (2005) and references therein

2. Pietra F. Secondary metabolites from marine microorganisms: bacteria, protozoa, algae and fungi. Achievements and prospects. Nat Prod Rep 14: 453-464 (1997)

3. Jensen PR, Fenical W. Marine microorganisms and drug discovery: current status and future potential. In Drugs from the Sea. Ed., N. Fusetani, pp. 6-29, Karger, Basel (2000)

4. Li Y, Li X, Son BW. Antibacterial and radical scavenging epoxycyclohexenones and aromatic polyols from a marine isolate of the fungus Aspergillus. Natural Product Sciences 11: 136-138 (2005)

5. Kirby GW, Robins DJ, Sefton MA, Talekar RR. Biosynthesis of bisdethiobis(methylthio)glitoxin, a new metabolites of Gliocladium deliquescens. JCS Perkin I. 119-121 (1980)

6. Lee HJ, Lee JH, Hwang BY, Kim HS, Lee JJ. Antiangiogenic acitivites of glitoxin and its methylthioderivative, fungal metabolites. Arch Pharm Res 24: 397-401 (2001) and references therein

7. Cole RJ, Cox RH. Handbook of toxic fungal metabolites. pp. 571-574, Academic Press, London (1981)

8. Li Y, Li X, Son BW, Choi HD. Screening of antimicrobial activity from the marine-derived fungus. Kor J Pharmacogn 34: 142-144 (2003)

9. Li XF, Li Y, Nam KW, Kim DS, Choi HD, Son BW. Screening of radical scavenging activity from the marinederived fungus. Kor J Pharmacogn 33: 219-223 (2002)

10. Turner WB, Aldridge DC. Fungal metabolites II. pp. 405-423, Academic Press, London (1983) 